\title{
Adhesion Properties of Commercial Wood Glue
}

\author{
Ayman E Muhammad, Hassan G Abd-Elgadir, Momin E. Abdalla, Taj Alasfia M Barakat* \\ Chemical Engineering Department, Faculty of Engineering, University of Khartoum, Al-Gamaa Ave, Al Khurtum, Sudan
}

\section{*Corresponding Author}

Taj Alasfia M Barakat

\section{Article History}

Received: 26.06 .2019

Accepted: 10.07 .2019

Published: 30.07 .2019

\begin{abstract}
Adhesives have become an inseparable part of our modern styled life where it is used in every aspect, field and industry. Adhesive have become the core of many industries. This paper aims to discuss the history, definition, working mechanism of adhesives and also to mention part of the literature available about adhesives like adhesives types, classes and the manufacturing process. Part of this paper is about experimenting samples of adhesives and materials. The results of the experiments proved that using the appropriate type of adhesive with the material in question results in far greater bonding strength than using inappropriate type of adhesive.
\end{abstract}

Keywords: Adhesive, Material, Bonding, Strength

\section{INTRODUCTION}

The first evidence of a substance being used as an adhesive dates back to 4000 B.C. Archaeologists have uncovered statues from Babylonian temples that have ivory eye balls glued into eye sockets. This tar-like glue has held for almost 6,000 years. The period of time between 1500-1000 B.C. gave further proofs that glue had become a method of assembly. Paintings and murals showed details of wood gluing operations [1]. A casket removed from the tomb of king tut shows the use of glue in its construction. Our museums today contain many art objects and furnishings from the tombs of Egyptian pharaohs that are bonded or laminated with some type of animal glue [2]. The first references in literature concerning glue and the art of glue appear about the year 200 B.C. Simple procedures for making and using animal glue were mentioned $[3,1]$.

The next period of activity is from 1-500 A.D. when the Romans and Greeks developed the art of veneering and marquetry, which is the bonding of thin sections or layers of wood. From this art, the making of animal and fish glues were refined and other types of adhesives were developed, such as an adhesive from egg whites to bond golf leaf. In addition to egg whites, other natural ingredients were used to prepare glue, such as blood, bones, hide, milk, cheese, vegetables, and grains [4, 5].

The Romans were one of the first to use tar and beeswax to caulk the planking in boats and ships.

A study of history shows the use of glue fell into disuse until about 1500-1700 A.D., when adhesives were used in the building of furniture. The secret of violins made by Antonio Stradivarius was the adhesive process used to laminate his specially treated woods. His methods have also been lost in antiquity and have not been rediscovered, even with today's sophisticated analytical methods. About 1700 A.D., the widespread use of glue brought about some rapid changes in the history of adhesives. The first commercial glue factory was started in Holland to manufacture animal glue from hides. About 1750, the first glue patent was issued in Britain for fish glue. Patents were then rapidly issued for adhesives using natural rubber, animal bones, fish, starch, and milk protein (casein) [2, 1]. By 1900, the United States had a number of factories producing glue from these bases. The industrial revolution caused an explosion in technical breakthroughs that resulted in new materials becoming available for use in formulating adhesives. The first plastic polymer to be synthesized was cellulose nitrate, a thermoplastic Material derived from the cellulose of wood. Its first use was in the manufacture of billiard balls, which had been made from ivory. The era of plastics began with the production of Bakelite phenolic, a thermoset plastic, in 1910. Within a year, adhesives using phenolic resin were put on the market [6]. The 1920s, 30s, and 40s saw many new plastics and rubbers synthetically produced, many out of an urgent necessity developed during World War II. Although adhesives have been known for about 6,000 years, most of the technology of adhesives has been developed during the last

Copyright @ 2019: This is an open-access article distributed under the terms of the Creative Commons Attribution license which permits unrestricted use, distribution, and reproduction in any medium for non commercial use (NonCommercial, or CC-BY-NC) provided the original author and source are credited. 
100 years. The development of plastics and elastomers has rapidly advanced the development of adhesives and has given formulators a wide variety of products that can change and improve various properties of adhesives, such as flexibility, toughness, curing or setting time, temperature and chemical resistance.

Adhesives touch our lives every day. They are never more than an arm's length away, even though we may not be aware of their presence. A description of some of the more common types of adhesives and their uses should make you more aware of how adhesives touch your life $[3,5]$.

The basic definition of an adhesive as used by the adhesive sealant council in America is: $\{$ A material used for bonding that exhibits flow at the time of application\}. An adhesive is a material used for holding two surfaces together. An adhesive must wet the surfaces adhere to the surfaces, develop strength after it has been applied, and remain stable [2].

\begin{abstract}
Adhesion Theory
There is no simple theory of adhesion, and the truth for any one system is probably a combination of adsorption, electrostatic attraction and diffusion. The three main theories are discussed below. For a material to perform as an adhesive it must have four main requirements It must "wet" the surfaces (that is it must flow out over the surfaces that are being Bonded, displacing all air and other contaminates that are present), It must adhere to the surfaces (that is after flowing over the whole surface area), It Must start to adhere and stay in position and become "tacky". Also It must develop strength (the material must now change its structure to become Strong or non-tacky but still adherent). Finally It must remain stable (the material must remain unaffected by age, environmental Conditions and other factors as long as the bond is required) [2]. Several theories of adhesion exist which are based on surface-chemical phenomena. It is generally considered that there is no generalized, unified theory of adhesion since the Phenomenon is known to exist between a great diversity of material types. In some special Cases, either pure adsorption, or electrical or diffusion attractive forces are found at an Adhesive-bound interface. More frequently, one finds adhesion to be a synergistic combination of all of these driving, attractive forces. This is especially true in the case of practically all adhesive bonding situations [7].
\end{abstract}

\title{
Adhesive Selection
}

The selection of an adhesive is a critical factor that will influence each step. The adhesive selection will be dependent primarily on one: the type and nature of substrates to be bonded, two: the methods of curing that are available and practical, three: the expected environments and stresses that the joint will see in Service. The adhesive selection process is difficult because many factors must be considered, and there is no universal adhesive that will fulfill every application. It is usually necessary to compromise when selecting a practical adhesive system. Some properties and characteristics that are desired will be more important than others, and a thought full prioritization of these criteria will be necessary in selecting an adhesive. One must first go about finding an adhesive that will satisfy the High priority requirements of the application. The lower priority "requirements' 'May then need to be compromised to find the best fit. One needs to optimize the entire bonding process and not merely a Single part of the process. Considerations need to be given at the same time to the substrates, joint design, surface pretreatment, quality control, application and curing methods, and other processes. Seldom is everything except the adhesive fixed. Very often, nothing is rigidly established, and it is up to the design engineer to not only to choose the Adhesive but also to decide on all of the peripheral processes, alternative substrates, processes, etc., should always be considered. For example a slight change in the application methods could open the door for consideration of an entirely new family of adhesives [2].

\section{Adhesives Advantages \\ Why use adhesive over mechanical joining methods?}

Some people are more inclined to trust a rivet or weld over an adhesive to secure two things together. Adhesives, however, overcome the limitations found in traditional methods of joining plastics and metals.

When it comes to joining plastics, mechanical fasteners, ultrasonic welding and solvent welding all have their place. Listed below are some common limitations of processes that adhesives can help solving:

\section{Mechanical Fasteners for Plastics}

Create stresses in the plastic/rubber that could lead to distortion or cracking require altering the design to allow for holes, create appearances that can interfere with the styling of the end product. Concentrate all the holding power at the fastener location causing the applied force to be carried by a small area of the plastic or rubber $[8,9]$.

\section{Ultrasonic Welding}

It Cannot be used on thermosets, cannot be used to join plastics/rubber to other substrates such as metal or glass and requires tighter design tolerances (small area to concentrate the ultrasonic energy is desirable). Limits the capability of joining different thermoplastics in the same assembly. Also it requires a large investment in machinery [9]. 


\section{Solvent Welding}

Cannot be used to join plastics/rubber to other substrates such as metal or glass, Cannot be used with thermoset plastics/rubber, it has a tendency to cause stress cracking, it also requires pre-set and consistent time between the application of the solvent and mating of the parts [9].

\section{Solvent Cements}

They have poor resistance to heat and solvents, Emit fumes that may be toxic or flammable, They Require ventilation \& extensive drying time Also Require design to avoid trapped solvent which may lead to weakness, plus they have poor gap filling capability and require a long time to achieve full strength.

As with plastics, methods of joining metals include mechanical fasteners and thermal joining methods. Limitations in these methods that adhesive joining can overcome are listed below [9].

\section{Mechanical fasteners for metals}

It Create stress concentration points, also they Are visible additions to the joint or seam, plus they have Limited load distribution points [9].

\section{Welding, brazing \& other thermal joining methods}

They tends to distort components, plus they require secondary operations (painting, grinding) to achieve an aesthetically pleasing appearance \& they Are limited to similar materials.

This work aims to review available literature about adhesives, summarize the history and background about adhesives. Main object was to understand the theories of adhesion and compare between different adhesives and other joining methods through experimental investigations.

\section{MATERIALS AND METHODS \\ MATERIALS}

The materials and methods were used in adhesive strength testing. Two tests were performed, such as the Peel (Tension) Test \& Sheer (Internal Bond or Bending) test using UTM (Universal Tensile Machine), which is also known as Universal Tensile Tester (see Fig-2 below). The peel \& sheer tests were performed according to ASTM D3930-8 Standard for Wood Adhesive Strength Testing \& ASTM D905-03 Standard Test Methods for Strength Properties of Adhesive Bond in Shear by Compression Loading [6].

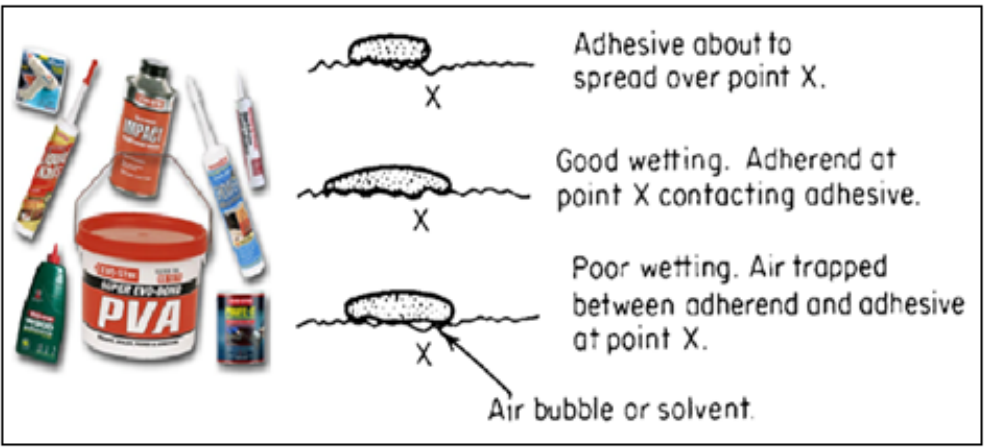

Fig-1: Commercial glue, illustration of good and bad adsorption between Adhesive and Surface

For each test three different adhesives were used, two are wood related and the other one is not wood related, each glue has one sample per test. Moski Wood was used as testing material. The tests to perform and adhesives used are tabulated below:
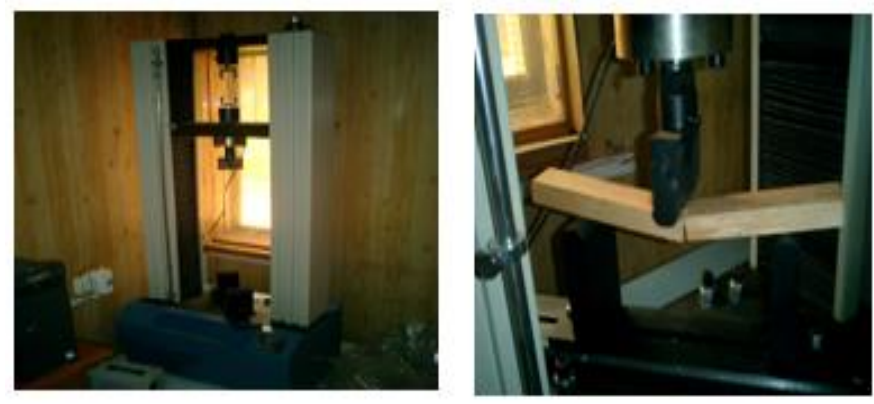

Fig-2: "UTM" machine and ASTM D3930-8 test 
Table-1: Materials and Adhesives

\begin{tabular}{|c|c|c|c|c|c|}
\hline Test Type & Adhesive Type & Maker & No. of Samples per Test & Standard Used & Machine Used \\
\hline \multirow{3}{*}{ Peel (Tension) Test } & Wood Glue & Manufacturer A & \multirow{2}{*}{1} & ASTM D3930-8 & UTM \\
\cline { 2 - 4 } & Wood Glue & Manufacturer B & & \\
\cline { 2 - 3 } & General Purposes & UHU & & & \\
\hline Loading (Bending) Test & Wood Glue & Manufacturer A & \multirow{2}{*}{1} & USTM D905-03 & \\
\cline { 2 - 3 } & Wood Glue & Manufacturer B & & \\
\cline { 2 - 3 } & General Purposes & Manufacturer C & & \\
\hline
\end{tabular}

\section{METHODS}

\section{Peel Test}

In this test the samples of equal size and geometry were glued together at the middle with the adhesive in question then on each side they were glued to the machine clamps using Hot Melt Adhesive (see Fig-3). Then samples were left for at least 24 hours to dry completely and were subjected to a uniformly increasing tensile force at both sides until the adhesive in the middle breaks.
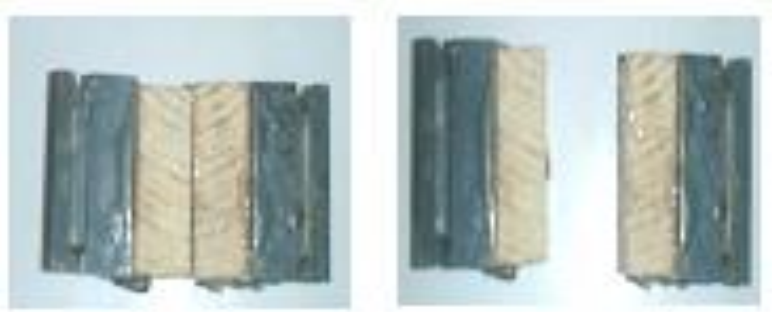

Fig-3: Hot melt adhesive and middle breaks

\section{Loading Test}

The samples are glued in the middle in finger joint type then are subjected to uniformly increasing pressure at the joining point (see Fig-3) till the glue reaches it is breaking point (see Fig-4).
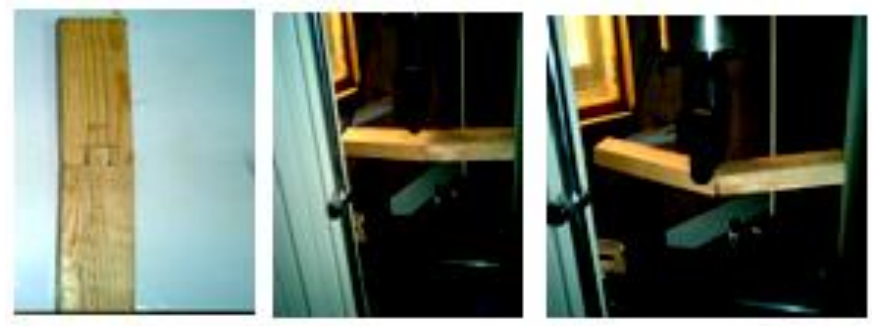

Fig-4: Loading test and final breaking point

\section{RESULTS AND DISCUSSION}

The results of the pervious experiments were displayed in details. Each result has discussed data of the load, time, the maximum peak and the breaking point load. The Peel as well as the Loading tests are performed for each glue sample as detailed below.

Table-2: Samples Dimensions According to ASTM D3930-8 \& ASTM D905-03 Manuals [6]

\begin{tabular}{|c|c|c|c|c|}
\hline Test & Material & $\begin{array}{c}\text { Length } \\
(\mathbf{m m})\end{array}$ & $\begin{array}{c}\text { Width } \\
(\mathbf{m m})\end{array}$ & $\begin{array}{c}\text { Thickness } \\
(\mathbf{m m})\end{array}$ \\
\hline Peel & Moski Wood & 50 & 50 & 25 \\
\hline Loading & Moski Wood & 25 & 50 & 25 \\
\hline
\end{tabular}

\section{Peel Tests}

\section{Manufacturer "A" Wood Glue}

In this test Moski Wood sample was used with Manufacturer "A" Wood Glue which was subjected uniformly to increase peel force at temperature of $23^{\circ} \mathrm{C}$ and Humidity Ratio $60 \%$. The sample actual dimensions were: Length \& Width: $47.310 \mathrm{~mm}$, Thickness: $24.415 \mathrm{~mm}$. The maximum force this sample could handle was $2.170 \mathrm{kN}$, (see Fig-6) but this force is the breaking point of the Hot Melt not the Wood Glue because the breaking happened at the side of the sample not the middle, so in conclusion this experiment was a failure because our purpose was to find the wood glue's breaking point force not the hot melt's. 


\section{Manufacturer "B" Wood Glue}

In this test Moski Wood sample was used with Manufacturer "B" Wood Glue which was subjected uniformly to increase peel force at temperature of $23^{\circ} \mathrm{C}$ and Humidity Ratio $60 \%$. The sample actual dimensions were: Length \& Width: $46.170 \mathrm{~mm}$, Thickness: $24.4 \mathrm{~mm}$. The maximum force this sample could handle was $1.610 \mathrm{kN}$ (see Fig-6), but this force is the breaking point of the Hot Melt not the Wood Glue because the breaking happened at the side of the sample not the middle, so in conclusion this experiment was a failure because the purpose was to find the wood glue's breaking point force not the hot melt's.

\section{Manufacturer "C" Wood Glue}

In this test Moski Wood sample was used with Manufacturer "C" Wood Glue which was subjected uniformly to increase peel force at temperature of $23^{\circ} \mathrm{C}$ and Humidity Ratio $60 \%$. The sample actual dimensions were: Length \& Width: $47.610 \mathrm{~mm}$, Thickness: $23.81 \mathrm{~mm}$. The maximum force this sample could handle was $3.740 \mathrm{kN}$ (see Fig-6), this force is the breaking point of the manufacturer "C" Glue because the breaking happened at the middle of the sample, so in conclusion this experiment was a success.
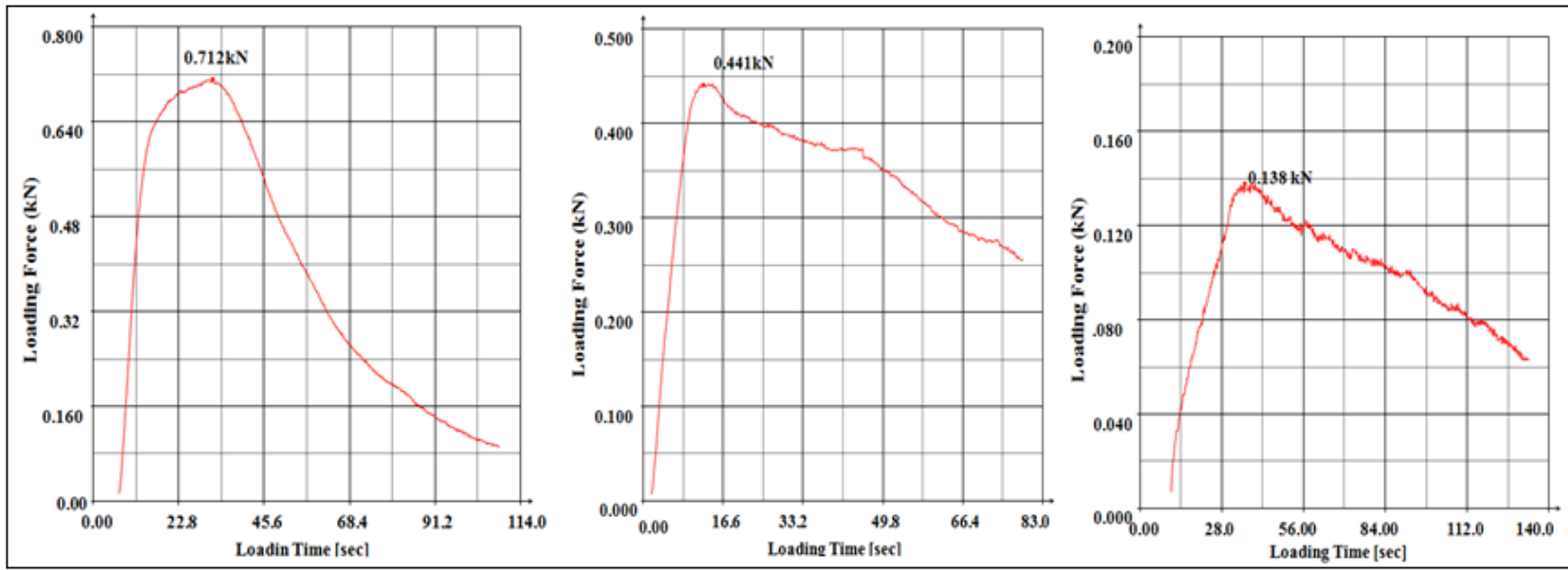

Fig-5: Loading test and final breaking point for "A, B, C" Wood Glue
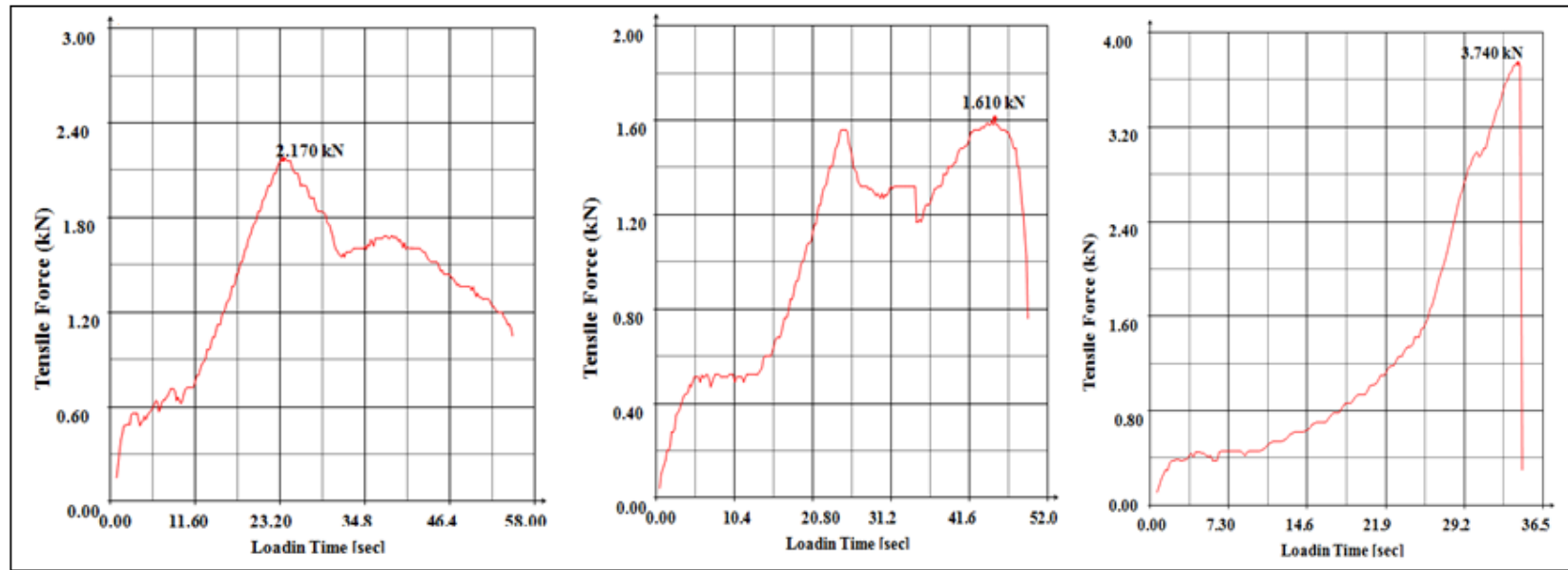

Fig-6: Peel test and final breaking point for "A, B, C" Wood Glue

\section{Loading Tests}

\section{Manufacturer "A" Wood Glue}

In this test Moski Wood sample was used with Manufacturer "A" Wood Glue which was subjected uniformly to increase loading force at temperature of $23^{\circ} \mathrm{C}$ and Humidity Ratio $60 \%$. The sample actual dimensions were: Length: $250.00 \mathrm{~mm} \&$ Width: 47.50 $\mathrm{mm}$, Thickness: $23.00 \mathrm{~mm}$. The maximum force this sample could handle was $0.712 \mathrm{kN}$ (see Fig-5) this force is the breaking point of the Manufacturer "A" Wood Glue because the breaking happened at the middle of the sample, so in conclusion this experiment was a success.

\section{Manufacturer "B" Wood Glue}

In this test Moski Wood sample was used with Manufacturer "B" Wood Glue which was subjected uniformly to increase loading force at temperature of $23^{\circ} \mathrm{C}$ and Humidity Ratio $60 \%$. The sample actual dimensions were: Length: $250.00 \mathrm{~mm} \&$ Width: $48.00 \mathrm{~mm}$, Thickness: $23.50 \mathrm{~mm}$. The maximum force this sample could handle was $0.411 \mathrm{kN}$ (see Fig-5), this force is the breaking 
point of the Manufacturer "B" Wood Glue because the breaking happened at the middle of the, so in conclusion this experiment was a success.

\section{Manufacturer "C" Wood Glue}

In this test Moski Wood sample was used with Manufacturer "C" Wood Glue which was subjected uniformly to increase loading force at temperature of $23^{\circ} \mathrm{C}$ and Humidity Ratio $60 \%$. The sample actual dimensions were : Length: $250.00 \mathrm{~mm} \&$ Width: $46.00 \mathrm{~mm}$, Thickness: $23.50 \mathrm{~mm}$. The maximum force this sample could handle was $0.138 \mathrm{kN}$ (see Fig-5), this force is the breaking point of the Manufacturer " $\mathrm{C}$ " Wood Glue because the breaking happened at the middle of the sample, so in conclusion this experiment was a success.

\section{CONCLUSIONS}

Adhesives are a very important part of our lives that cannot be disposed of and it is nearly in every aspect and field in the professional or domestic environment. This work discussed rigorous data on adhesion theory and applications.

- The history, definition and adhesion theories of adhesives, as well as the raw materials used in adhesives manufacturing, classes and types of adhesives, biological adhesives and the manufacturing process of adhesives, were covered in details.

- The work centered about tests methods, standards, mechanism of adhesion, purpose and the materials and adhesives types. The experimental work was applied among different tests in realty and the results of these tests were discussed in details.

- The work come to a definite and unquestionable results that using appropriate type of glue results in the most effective bonding.

- It is recommended to do more tests in different conditions i.e. higher or lower temperatures and humidity ratios, longer holding period, diverse glue types, various machines and materials, because in doing so a larger amount information is gained for comparison and obtaining more concrete result about whether using an appropriate adhesive with the material affects the bonding strength and durability.

\section{REFERENCES}

1. Skeist, I., \& Miron, J. (1990). Introduction to adhesives. In: Skeist, I. (Ed.), Handbook of Adhesives. (3rd), Van Nostrand Reinhold, New York, chap 1.

2. Skeist. (1997). Handbook of Adhesives, 3rd edn Van Nostrand-Reinhold, New York.

3. Kinloch, A. J. (1987). Adhesion and Adhesives: Science and Technology. Chapman and Hall, London.

4. Oman, S., \& Ken, C. (1971). In: Alner, D. J. (Ed.), Aspects of Adhesion, 6. University of London Press, London, 64.

5. Kinloch, A. J. (Ed.) (1983). Durability of Structural Adhesives. Applied Science Publishers, London.

6. Standard Specification for Adhesives for Wood-Based Materials for Construction of Manufactured Homes, www.astm.org, (Accessed January, 2019).

7. Schultz, J., \& Nardin, M. (2003). Theories and mechanisms of adhesion. In: Pizzi, A., \& Mittal, K. L. (Eds.), Handbook of Adhesive Technology (2nd ed.). Marcel Dekker, New York, chap. 3.

8. Temin, J. C. (1985). Adhesive compositions. Wiley-Interscience, Encyclopedia of Polymer Science and Engineering., 1, 547577.

9. Shields, J. (1984). Adhesives Handbook, 3rd edn, Butterworths, London. 